\title{
Effect of intestinal parasites on anaerobic performance and muscle strength in athletes
}

\author{
Tuğba KOCAHAN', Bihter AKINOĞLU², Adnan HASANOĞLU1 \\ ${ }^{1}$ Ministry of Youth and Sports, Sports General Directorship, Department of Health Services, Center of Athlete Training and Health Research, \\ Ankara, Turkey \\ ${ }^{2}$ Department of Physiotherapy and Rehabilitation, Faculty of Health Sciences, Ankara Yıldırım Beyazıt University, Ankara, Turkey \\ Correspondence \\ Tuğba KOCAHAN \\ Altay Mah. Şehit Mehmet Çavuş Cad. 1. Etap Eryaman 06793 Ankara, Türkiye \\ e-mail:kocahantu@gmail.com
}

\section{ABSTRACT}

Athletes have the risk of transmitting intestinal parasites in sports environments, leading to their poor performance. This study aimed to investigate iron deficiency, iron deficiency anemia, anaerobic performance, and muscle strength in athletes with intestinal parasites. It was conducted by the Ministry of Youth and Sports, General Directorate of Sports Services, Department of Health Affairs in 2018. The stool test results of the athletes were examined. The iron deficiency, iron deficiency anemia, anaerobic performance, and muscle strength were determined by stool sample analysis (study group) and compared with those of 28 athletes who performed the same sports and had no parasites (control group). The iron deficiency and iron deficiency anemia in all athletes were evaluated using iron and ferritin levels in blood analysis. The anaerobic performance was assessed using the Wingate test. The isokinetic muscle strength was evaluated using the IsoMed 2000 isokinetic dynamometer. No statistically significant difference in blood analysis and iron and ferritin levels was found between the groups. No athlete had iron deficiency or iron deficiency anemia. On comparing the anaerobic performances of the groups, no statistically significant difference in WanT parameters was observed. A statistically significant difference was found in the strength of the dominant leg knee extensor muscles at an angular velocity of $60 \%$ s, but no statistically significant differences were noted in other muscle strength parameters. Asymptomatic intestinal parasites did not lead to iron deficiency or iron deficiency anemia and did not affect anaerobic performance in athletes, but adversely affected the strength of dominant leg knee extensor muscles.

Key words: Anemia, infection, isokinetic, sport, Wingate test

\section{INTRODUCTION}

Intestinal parasitic infections occur when the protozoa or helminths settle in the small intestine and/or large intestines. Intestinal parasitic infections are among the most common infections worldwide, especially in developing countries, and are a serious public health concern. It is an important cause of morbidity and mortality in children and high-risk groups. Studies have shown that intestinal parasites adversely affect the health and development of children and cause loss of work and power in adults (1-5). Intestinal parasites are common in both children and adults due to the fact that hygiene habits in children are not acquired sufficiently and adults are more likely to encounter parasites in daily life (2). The causes of intestinal parasites include low levels of development in countries, mild climate characteristics, low socioeconomic status and educational level, lack of personal and environmental hygiene, and inadequate access to clean drinking and potable water $(2,4-6)$. Socio- economic situation, hygiene, and education levels in Turkey, which vary depending on the prevalence of intestinal parasites in different geographical regions, have reached $90 \%$ in some endemic areas $(2,5,7)$.

The symptoms of intestinal parasitic infections include abdominal pain, constipation or long-lasting diarrhea, sensation of gas and tension in the abdomen, change in the appearance of feces, bloody mucous stools, rectal fullness, anal itching, bloating, nausea and vomiting, appetite problems, weight loss, sleep disorder, irritability, and other symptoms such as fatigue, burnout symptoms, skin rashes, eczema, urticaria, muscle aches, joint pain, iron deficiency anemia, iron deficiency, growth and mental retardation, and rectal prolapses $(8,9)$. After treating these infections, the symptoms such as anemia, iron deficiency, weakness, muscle weakness during the infection, and dysregulation of the gastrointestinal system need to be relieved. 
Athletes are at risk of intestinal parasitic infections due to poor environmental conditions in sports settings. Public areas, such as preparatory camps, national team camps, and/or boarding camp training centers, besides frequent travel, expose athletes to poor hygiene conditions in terms of food and environment (10). At the same time, the immune system is frequently suppressed in athletes who perform long-term and severe exercises (11). Thus, after severe exercise, athletes become more susceptible to microorganisms, especially viral infections. After heavy exercise, viruses and bacteria can enter the body to increase the risk of subclinical and clinical infections (12). These conditions may lead to poor performance (13-15).

Intestinal parasites may cause anemia in athletes and adversely affect sports performance (16, 17). The hemoglobin concentration is low in anemia. The most common cause is iron deficiency. Iron is an important mineral for optimal athletic performance due to its role in energy metabolism, transport of oxygen, and acid-base balance. It promotes athletic performance by increasing oxygen-carrying capacity (30). The reduced iron tank adversely affects aerobic capacity, muscle strength, and endurance $(16,17)$.

The gastrointestinal tract is an important part of the immune system and nutrition. A well-balanced gastrointestinal tract, adequate and balanced nutrition of the athlete, bioavailability of the food, and optimization of the immune system are important for promoting sports performance. Hence, it is hypothesized that anaerobic performance and muscle strength are adversely affected in the elite athletes with intestinal parasites due to the effects of parasites on the gastrointestinal system and deterioration of nutrition. Therefore, this study aimed to determine the presence of iron deficiency anemia or iron deficiency in athletes with intestinal parasites and examine the muscle strength and anaerobic performance.

\section{MATERIALS AND METHODS}

This study was conducted by the Ministry of Youth and Sports, General Directorate of Sports Services, Department of Health Affairs in 2018. The stool test results of the athletes applying for health and performance evaluation were examined. The study was performed with a total of 56 athletes: 28 athletes who had parasites detected in the stool sample analysis and had no other disease (study group) and 28 athletes who did not have any parasites and did not have any known diseases (control group). The study group and the control group athletes were demographically similar (Table 1).

The permission and approval of the Ministry of Youth and Sports, General Directorate of Sports Services, Department of Health Affairs (dated 28.12.2018 and numbered 39746592-100-E.809306) were obtained to perform the study and use the data of the athletes who met the research criteria.

The first-day blood tests and stool tests were performed for all athletes participating in the study. The athletes were administered the anaerobic capacity test on the same day, and the isokinetic muscle strength test was conducted the next day. All athletes were informed before the tests and asked to put on sportswear and sports shoes.

Table 1: Descriptive characteristics of the groups

\begin{tabular}{|c|c|c|c|c|}
\hline & \multicolumn{2}{|c|}{$\begin{array}{l}\text { Study group } \\
\qquad(n=28)\end{array}$} & $\begin{array}{l}\text { Control group } \\
\quad(n=28)\end{array}$ & $\mathrm{P}$ \\
\hline Age (year) & & \pm 1.69 & $17.07 \pm 1.53$ & $0.681^{*}$ \\
\hline Height (cm) & & \pm 9.70 & $174.68 \pm 9.18$ & $0.997^{*}$ \\
\hline Weight (kg) & & \pm 13.27 & $68.72 \pm 14.34$ & $0.921^{*}$ \\
\hline BMI $\left(\mathrm{kg} / \mathrm{m}^{2}\right)$ & & \pm 3.04 & $22.51 \pm 3.28$ & $0.894^{*}$ \\
\hline Sports age (year) & & $-11)$ & $5.50(3-9)$ & $0.959^{* *}$ \\
\hline \multirow{2}{*}{ Gender, n (\%) } & Male & $20(72)$ & $20(72)$ & \\
\hline & Female & $8(28)$ & $8(28)$ & \\
\hline
\end{tabular}

BMI, Body mass index. *Independent-samples t test. ${ }^{* *}$ Mann-Whitney U test. 


\section{Blood analysis}

The fasting blood sample was taken from the antecubital vein of the athletes on the first day. It was collected in two tubes [one containing EDTA, and the other containing a clot activator (SST II Advance)].

Red blood cell (RBC) count, hemoglobin (HGB), hematocrit (HCT), mean corpuscular volume (MCV), mean corpuscular hemoglobin $(\mathrm{MCH})$, red cell distribution width (RDW), white blood cell (WBC) count were measured using the Sysmex CBC XT2000I counter (Sysmex Corporation, Kobe, Japan). Impedance was used for RBC count, photometric analysis for $\mathrm{HGB}$, cumulative impedance for $\mathrm{HCT}$, and fluorescence flow cytometry for WBC count. The MCV and $\mathrm{MCH}$ values were calculated using the RBC count and HCT. Randox RX Imola (UK) clinical chemistry device was used to measure iron ( $\mathrm{Fe}$ ) and ferritin values. Spectrophotometry was used for iron (Fe), and turbidimetry methods were used for ferritin value.

\section{Stool sample analysis}

Before the analysis, the athletes were given special closed plastic containers for stool collection, and the stool samples were studied within $1 \mathrm{~h}$. The stool samples were first examined macroscopically. Then, two samples were prepared with $22 \times 22$ lamellae using saline solution with the Olympus CX23LEDRFS1 model light microscope having zigzag scanning with $10 x$ lens and then one-third of the lamella with $40 x$ lens. The same biologist examined all the materials. The type of parasite was determined in the 40x lens examination.

\section{Evaluation of anaerobic capacity}

The Wingate test (WanT) was used to evaluate the anaerobic capacity of the athletes. WanT is a test to measure the explosive force, which is continuity in strength and muscular fatigue, to obtain information about muscle metabolism in short-term and high-intensity exercises, and also to evaluate athletic performance. The Monark 891E model leg bicycle ergometer, which was connected to the modified computer for WanT and worked with compatible software, was used. The saddle and pedal length settings were made for each athlete before the test. In the lowerextremity WanT, the load equivalent to $7.5 \%$ of body weight was calculated automatically on the computer and placed on the scale. Before starting WanT, the athletes cycled the bike for about 3 min with 60-80 pedal speed (rpm). In the last $5 \mathrm{~s}$ of every $1 \mathrm{~min}, \mathrm{a}$ high-speed load of 120-160 rpm was applied. After completing the warm-up, the athletes performed a 2-min stretch, following which they were allowed to cool down. When the athlete was ready, the test was started and the driver was asked to pedal for $30 \mathrm{~s}$. The number of pedals and load at the end of $30 \mathrm{~s}$ was calculated, and total work = anaerobic capacity (in Joule) was determined. With the mathematical mean of the total work, the average job = anaerobic power was calculated (in Watt). During WanT, the highest power value during any $5 \mathrm{~s}$ (initial seconds) was recorded as the peak power, which was an indicator of the anaerobic energy capacity. The minimum power value in $5 \mathrm{~s}$ (last seconds) was recorded as the minimum power. The fatigue index was calculated by using the following formula: (peak power - minimum power/peak power) $\times 100$. After completing the test, the athlete was allowed low-speed cooling for $3 \mathrm{~min}$, and the test was terminated (18).

\section{Evaluation of isokinetic muscle strength}

The isokinetic muscle strength of the knee flexor and extensor muscles was evaluated using the IsoMed 2000 device. The athletes underwent a warmup run for 10 min before the test. After the warm-up, they were taken to the isokinetic device, and the device was adjusted according to the individual anthropometric structure of the athletes. During the test, the body weight and age values were entered into the computer and the program was installed. The suitability of the movement width of the joint and the angles to be tested was determined by making a sample movement at very low speed to the athletes. The effect of gravity was reset. Evaluations were done in the sitting position, taking into account the range of motion of the athletes and the measurement characteristics of the device. Accordingly, the knee flexion/extension movement was performed between $90^{\circ}$ and $0^{\circ}$ flexion angles in the sitting position while the trunk was at $70^{\circ}$ flexion. The evaluation protocol was created in two stages for each angular velocity. In the first stage, the athletes were asked to perform three repetitive submaximal movements at $60 \% \mathrm{~s}$ for familiarization to the movement and for warming up. In the second stage, the test was completed by making a maximum of five repetitive motions 
at $60 \%$ angular velocity. Similarly, the athletes were asked to perform three repetitive submaximal movements at $180 \%$ s for familiarization to the new angular velocity and for warming up. In the second stage, the test was completed by making maximal 15 repetitive motions at $180 \%$ s angular velocity. Between maximal movements, one minimum rest break was given. Peak torque (PT) and PT/kg values of the athletes at both angular speeds were recorded. Measurements were taken bilaterally, first on the dominant side and then on the nondominant side. The athletes were encouraged to perform maximal performance with verbal commands. All tests were performed by the same physiotherapist who worked for at least 3 years in this area (19).

\section{Statistical analysis}

All the data obtained from the groups were analyzed using the Statistical Package for Social Sciences Inc. (SPSS, IL, USA) for Windows Release 20.0 statistical package program. The variables determined by measurement were expressed as mean \pm standard deviation $(X \pm S D)$, and the percentage (\%) value was calculated for the variables by counting. For comparing two groups in terms of numerical variables, the independent-samples $t$ test was used for parametric data and the Mann-Whitney $U$ test was used for nonparametric data. In all statistics, a P value less than 0.05 indicated statistical significance.

\section{RESULTS}

The age, height, weight, body mass index, sports age, and gender distribution of the study and control groups were similar $(P<0.05)$ (Table 1$)$.

In the study group, the distribution of parasites was determined as Ascaris lumbricoides in eight cases (28.6\%), Taenia saginata in eight cases (28.6\%), E. histolytica in seven cases (25\%), Entamoeba coli in three cases (10.7\%), and Giardia intestinalis in two cases $(7.1 \%)$ (Table 2 ).

No statistically significant difference in blood analysis and iron and ferritin levels was found between the groups ( $P>0.05)$, and no athlete had iron deficiency or iron deficiency anemia (Table 3).

When the anaerobic performances of the groups were compared, no statistically significant difference was observed in total work, average work, peak power, minimum power, and fatigue index between the groups $(P>0.05)$ (Table 4).
When the isokinetic muscle strength values of the groups were compared, the strength of the dominant leg knee extensor muscles was found to be less in the study group at the angular velocity of $60 \% / \mathrm{s}$ $(P<0.05)$. No statistically significant difference was observed in the other muscle strength parameters evaluated at angular velocities of $60 \% \mathrm{~s}$ and $180 \% \mathrm{~s} \mathrm{(P}$ $>0.05$ ) (Table 5).

\section{DISCUSSION}

This study examined iron deficiency anemia, anaerobic performance, and muscle strength in athletes with intestinal parasites who were asymptomatic without any clinical complaints. It was found that iron deficiency or iron deficiency anemia did not develop in athletes with intestinal parasites and anaerobic performance was not affected. The explosive muscle strength of the dominant leg knee extensor muscle was found to be less in the study group with intestinal parasites.

Intestinal parasitic infections are one of the most common infections worldwide. A. lumbricoides, Trichuris trichiura, and hookworm are the most common intestinal parasites from soil-borne helminths (20). Giardia lamblia, which causes giardiasis, is the most common intestinal protozoan in developed and developing countries (21). Another common bowel protozoan is E. histolytica, which frequently causes chronic bowel infection (22). In Turkey, various studies were conducted to investigate the distribution of parasites by age groups. G. intestinalis with Enterobius vermicularis was reported in the 0-14 age group. Blastocystis hominis and G. intestinalis were more frequently found in adulthood and childhood, respectively (2). A retrospective study examining the prevalence of intestinal parasites in the

Table 2: Proportional distribution of intestinal parasites detected in the study group

\begin{tabular}{lcc}
\hline Detected intestinal parasites & Total number & $\%$ \\
\hline Ascaris lumbricoides & 8 & 28.6 \\
Taenia saginata & 8 & 28.6 \\
Entamoeba histolytica & 7 & 25 \\
Entamoeba coli & 3 & 10.7 \\
Giardia intestinalis & 2 & 7.1 \\
\hline
\end{tabular}


Table 3: Blood test results of the groups

\begin{tabular}{lccc}
\hline Blood parameters & $\begin{array}{c}\text { Study group } \\
(\mathrm{n}=28)\end{array}$ & $\begin{array}{c}\text { Control group } \\
(\mathrm{n}=28)\end{array}$ & $\mathrm{P}^{*}$ \\
\hline $\mathrm{RBC}\left(\times 10^{6} / \mu \mathrm{L}\right)$ & $5.22 \pm 0.44$ & $5.32 \pm 0.45$ & 0.434 \\
Hemoglobin $(\mathrm{g} / \mathrm{dL})$ & $15.35 \pm 1.25$ & $15.35 \pm 1.25$ & 0.684 \\
Hematocrit $(\%)$ & $43.39 \pm 3.94$ & $43.84 \pm 3.54$ & 0.652 \\
$\mathrm{MCV}(\mathrm{fL})$ & $83.02 \pm 3.39$ & $82.53 \pm 3.87$ & 0.617 \\
$\mathrm{MCH}(\mathrm{pg})$ & $29.03 \pm 1.49$ & $28.92 \pm 1.43$ & 0.771 \\
$\mathrm{RDW}(\%)$ & $12.34 \pm 0.51$ & $12.44 \pm 0.70$ & 0.556 \\
WBC $\left(\times 10^{3} / \mu \mathrm{L}\right)$ & $7.35 \pm 2.65$ & $7.11 \pm 2.40$ & 0.730 \\
Iron $(\mu \mathrm{g} / \mathrm{dL})$ & $87.39 \pm 39.50$ & $83.85 \pm 31.49$ & 0.713 \\
Ferritin $(\mathrm{ng} / \mathrm{mL})$ & $49.00 \pm 23.82$ & $54.90 \pm 26.44$ & 0.385 \\
\hline
\end{tabular}

$M C H$, Mean corpuscular hemoglobin; $M C V$, mean corpuscular volume; $R B C$, red blood cell; $R D W$, red cell distribution width; WBC, white blood cell. *Independent-samples t test.

Table 4: Wingate test results of the groups

\begin{tabular}{llll}
\hline Wingate test parameters & $\begin{array}{l}\text { Study group } \\
(\mathrm{n}=28)\end{array}$ & $\begin{array}{l}\text { Control group } \\
(\mathrm{n}=28)\end{array}$ & $\mathrm{P}^{*}$ \\
\hline PP $(\mathrm{W})$ & $878.91 \pm 267.80$ & $822.27 \pm 245.70$ & 0.413 \\
PP $(\mathrm{W} / \mathrm{kg})$ & $12.52 \pm 2.60$ & $12.13 \pm 2.74$ & 0.584 \\
tPP (ms) & $1582.29 \pm 742.09$ & $1821.29 \pm 914.64$ & 0.288 \\
AP (W) & $583.25 \pm 169.52$ & $555.88 \pm 150.63$ & 0.526 \\
AP (W/kg) & $8.30 \pm 1.48$ & $8.21 \pm 1.61$ & 0.837 \\
MP (W) & $296.07 \pm 144.82$ & $299.46 \pm 117.21$ & 0.924 \\
MP (W/kg) & $4.25 \pm 1.90$ & $4.41 \pm 1.54$ & 0.724 \\
PD (W) & $582.84 \pm 231.71$ & $522.81 \pm 207.57$ & 0.312 \\
PD (W/kg) & $8.28 \pm 2.80$ & $7.71 \pm 2.82$ & 0.453 \\
PD (W/s) & $19.86 \pm 8.31$ & $17.61 \pm 7.34$ & 0.288 \\
PD $[W /(\mathrm{s} / \mathrm{kg})]$ & $0.29 \pm 0.11$ & $0.26 \pm 0.12$ & 0.412 \\
PD (\%) & $65.56 \pm 15.38$ & $62.41 \pm 12.90$ & 0.410 \\
\hline
\end{tabular}

*Independent-samples $t$ test.

province of Istanbul found the prevalence to be $5 \%$ $(5486 / 111,889)$. The most commonly detected four parasites were as follows: $G$. intestinalis (62\%), E. vermicularis (16\%), A. lumbricoides (7\%), and B. hominis (6\%) (6). Similarly, in a retrospective study in Sivas province, the prevalence of intestinal parasites was found to be $10.5 \%$ (532/5057). The most common parasites were G. intestinalis (3.7\%), E. histolytica/ dispar (2.4\%), E. coli (2.5\%), and lodamoeba butschlii (0.6\%) (23). No published study examined the prevalence of intestinal parasites in athletes. In this study, A. lumbricoides, T. saginata, E. histolytica, E. coli, and G. intestinalis were found in $8(28.6 \%), 8$ (28.6\%), 7 (25\%), $3(10.7 \%)$, and (7.1\%) cases, respectively.

Athletes are at risk of transmission of intestinal parasites in sports environments. Contamination 
Table 5: Isokinetic muscle power parameters of the groups

\begin{tabular}{|c|c|c|c|c|c|c|}
\hline \multicolumn{4}{|c|}{ Parameters of isokinetic muscle force measurement } & \multirow{2}{*}{$\begin{array}{l}\text { Working group } \\
(\mathrm{n}=28)\end{array}$} & \multirow{2}{*}{$\begin{array}{l}\text { Control group } \\
(n=28)\end{array}$} & \multirow{2}{*}{$\frac{P^{*}}{0.457}$} \\
\hline \multirow{5}{*}{$\begin{array}{l}60 \\
\% / s\end{array}$} & \multirow{5}{*}{\multicolumn{2}{|c|}{$\begin{array}{l}\text { Flexion } \\
\text { DM PT/W (Nm/kg) } \\
\text { NDM PT(Nm) } \\
\text { NDM PT/W(Nm/kg) } \\
\text { Symmetry index (\%) }\end{array}$}} & DM PT (Nm) & & & \\
\hline & & & $1.61 \pm 0.31$ & $1.55 \pm 0.29$ & 0.444 & \\
\hline & & & $72.06 \pm 63.34$ & $71.98 \pm 61.12$ & 0.996 & \\
\hline & & & $12.20 \pm 15.39$ & $10.99 \pm 13.10$ & 0.752 & \\
\hline & & & $144.26 \pm 67.31$ & $135,33 \pm 64,56$ & 0.614 & \\
\hline & \multirow{5}{*}{\multicolumn{2}{|c|}{$\begin{array}{l}\text { Extension } \\
\text { DM PT/W(Nm/kg) } \\
\text { NDM PT(Nm) } \\
\text { NDM PT/W(Nm/kg) } \\
\text { Symmetry index (\%) }\end{array}$}} & DM PT(Nm) & $129.24 \pm 113.42$ & $132,74 \pm 113,17$ & 0.908 \\
\hline & & & $2.47 \pm 1.05$ & $3.13 \pm 1.03$ & $0.021^{* *}$ & \\
\hline & & & $148.19 \pm 84.85$ & $149.81 \pm 80.76$ & 0.942 & \\
\hline & & & $21.88 \pm 24.54$ & $22.42 \pm 25.08$ & 0.935 & \\
\hline & & & $108.86 \pm 25.87$ & $101.07 \pm 17.19$ & 0.190 & \\
\hline & \multicolumn{3}{|c|}{ DM Flex/Ext conventional rate (\%) } & $34.58 \pm 27.55$ & $30.74 \pm 24.76$ & 0.586 \\
\hline & \multicolumn{3}{|c|}{ NDM Flex/Ext conventional rate (\%) } & $36.73 \pm 29.94$ & $35.68 \pm 28.05$ & 0.892 \\
\hline & \multirow[t]{5}{*}{ Flexion } & DM PT (Nm) & & $67.52 \pm 41.28$ & $64.03 \pm 40.79$ & 0.751 \\
\hline & & DM PT/W (Nm/kg) & & $81.33 \pm 106.84$ & $74.58 \pm 97.03$ & 0.806 \\
\hline 180 & & NDM PT(Nm) & & $58.59 \pm 51.35$ & $54.38 \pm 46.20$ & 0.748 \\
\hline \%sn & & NDM PT/W(Nm/kg) & & $1.54 \pm 0.92$ & $2.00 \pm 1.28$ & 0.128 \\
\hline & & Symmetry index (\%) & & $84.53 \pm 21.25$ & $85.32 \pm 24.14$ & 0.897 \\
\hline & \multirow[t]{5}{*}{ Extension } & DM PT(Nm) & & $116.06 \pm 60.25$ & $112.03 \pm 56.60$ & 0.798 \\
\hline & & DM PT/W(Nm/kg) & & $38.26 \pm 46.42$ & $44.28 \pm 54.80$ & 0.659 \\
\hline & & NDM PT(Nm) & & $137.35 \pm 48.28$ & $135.11 \pm 35.48$ & 0.844 \\
\hline & & NDM PT/W(Nm/kg) & & $39.63 \pm 49.87$ & $36.33 \pm 46.52$ & 0.799 \\
\hline & & Symmetry index (\%) & & $60.00 \pm 48.35$ & $60.10 \pm 48.73$ & 0.994 \\
\hline & \multicolumn{3}{|c|}{ DM Flex/Ext conventional rate (\%) } & $37.95 \pm 29.22$ & $36.69 \pm 28.08$ & 0.871 \\
\hline & \multicolumn{3}{|c|}{ NDM Flex/Ext conventional rate (\%) } & $45.08 \pm 19.60$ & $43.38 \pm 18.95$ & 0.743 \\
\hline
\end{tabular}

*Independent-samples $t$ test. ${ }^{* * P}<0.05$.

usually occurs due to fecal-oral administration, water and food during travel, shared living spaces, and sharing of personal belongings. Intestinal parasites can cause intestinal bleeding or malabsorption by destroying the absorption of nutrients, abdominal distension, abdominal pain, nausea, vomiting, diarrhea, and loss of food due to anorexia; these effects can cause dehydration due to fluid loss, leading to protein-energy malnutrition, anemia, and other nutritional deficiencies $(14,22,24-28)$. These symptoms may affect sports performance in athletes $(16,17)$. Intensive training during intestinal parasitic infection and treatment process may be objectionable (13). In general, bed rest and progression to normal training are recommended when the disease is systemic (12).
Iron deficiency is the most common nutrient deficiency worldwide. Malnutrition, insufficient iron absorption, and blood loss are the main causes of iron deficiency anemia $(29,30)$. The presence of intestinal parasites may lead to iron deficiency or iron deficiency anemia, resulting in malnutrition, iron malabsorption, or intestinal bleeding $(8,9)$. Iron deficiency negatively affects athletic performance by reducing the oxygen-carrying capacity (31). In the present study, the groups with intestinal and nonintestinal parasites had similar blood analysis results and iron and ferritin levels; no athlete had iron deficiency or iron deficiency anemia. The absence of any symptoms and signs in the working-group athletes suggested that the intestinal parasites did not cause 
any disease. This was probably related to the lack of iron deficiency or iron deficiency anemia in athletes.

Intense exercise causes immunosuppression, and moderate exercise activates the immune system against the diseases (32-34). Natural immunity to intestinal parasites is weak. These parasites are resistant to elimination from the host with a specific immune response. Hence, most of the intestinal parasites are chronic; they can adapt to the host's natural defense mechanisms and continue to multiply (35). In the present study, the anaerobic endurance of the athletes with intestinal parasites and the similarity in some muscle strength parameters could be attributed to the fact that the athletes in the study group were asymptomatic and had no iron deficiency or iron deficiency anemia. In addition, all the athletes in the study group were at the elite level and were subjected to regular and severe exercise loadings. Therefore, while the acute effects of exercise are disadvantageous for athletes in terms of predisposition to infection, the chronic effects of exercise strengthen immunity in an advantageous manner.

During high-intensity exercise, such as isokinetic strength tests, the muscles demand high energy. Due to reasons such as malnutrition or malabsorption, energy restrictions limit the performance of high-intensity exercise (36). In a previous study, the muscle strength of the leg flexor muscles was shown to be related to the amount of protein taken (37). In the present study, when the isokinetic muscle strength values of the groups were compared, the explosive muscle strength of the dominant leg knee extensors was better in the control group. It was presumed that the explosive force of the athletes might be affected by the presence of intestinal parasites. The results showed the nutritional status of athletes with intestinal parasites. The athletes had no iron deficiency, but the absorption capacity of the gastrointestinal tract was impaired and the explosive muscle strength was adversely affected. Further studies are needed to clarify this situation.

In conclusion, intestinal parasites, which were asymptomatic in the present study, do not cause iron deficiency or iron deficiency anemia in athletes. Also, they do not adversely affect anaerobic power. Symptoms may occur at the time of weakening of the system. Therefore, intestinal parasitic infections should be treated when detected and periodic health checks must be added to the stool sample analysis. This study showed that asymptomatic intestinal parasites, which did not lead to iron deficiency or iron deficiency anemia, had a negative effect on the explosive strength of the dominant leg knee extensor muscles in athletes. This may be due to the fact that the gastrointestinal tract of the athletes is affected by intestinal parasites, leading to the negative impact of the nutrients on the intestine. Further studies with longer follow-up are needed to investigate the effects of intestinal parasites.

\section{REFERENCES}

1. Mohammad K, Mohammad A, Mohammad F, Mohammad Y, Timsah A. The Prevalence and associated risk factors of Intestinal Parasiticlnfections among school children living in Rural and Urban communities in Damietta Governorate. Egypt Academ Arena. 2012;4(5):90-7.

2. Usluca S, Yalçin G, Over L, Tuncay S, Sahin S, Inceboz T, Aksoy U. [The distribution of intestinal parasites detected in the Dokuz Eylul University Medical Faculty Hospital between 2003 and 2004]. Turkiye Parazitol Derg. 2006;30(4):308-12.

3. Balcı YI, Türk M, Polat Y, Erbil N. Denizli'deki Çocuklarda İntestinal Parazitlerin Dağııımı. Türkiye Parazitoloji Dergisi. 2009; 33 (4): $298-300$.

4. Organization $\mathrm{WH}$. Test procedures for insecticide resistance monitoring in malaria vectors, bio-efficacy and persistence of insecticides on treated surfaces: report of the WHO informal consultation, Geneva, 28-30 September 1998. Geneva: World Health Organization; 1998

5. Östan İ, Kilimcioğlu AA, Girginkardeșler N, Özyurt BC, Limoncu $M E, O k U ̈ Z$. Health inequities: lower socio-economic conditions and higher incidences of intestinal parasites. BMC Public Health. 2007;7(1):342.

6. Uysal HK, Akgül Ö, Purisa S, Öner YA. İstanbul Üniversitesi İstanbul Tıp Fakültesi'nde 25 Yıllık İntestinal Parazit Prevalansı: Retrospektif Bir Çalışma. Turkiye Parazitol Derg. 2014;38:97-101.

7. Okyay P, Ertug S, Gultekin B, Onen O, Beser E. Intestinal parasites prevalence and related factors in school children, a western city sample-Turkey. BMC public health. 2004;4(1):64-69.

8. Oberhelman RA, Guerrero ES, Fernandez ML, Silio M, Mercado D, Comiskey N, Ihenacho G, Mera R. Correlations between intestinal parasitosis, physical growth, and psychomotor development among infants and children from rural Nicaragua. Am J Trop Med Hyg. 1998 Apr;58(4):470-5. 
9. Kaya S, Çetin ES, Akçam Z, Kesbiç H, Demirci M. Entamoeba coli ve Blastocystis hominis saptanan olgularda klinik semptomlar. Türkiye Parazitol Derg. 2005;29(4):229-31.

10. Patel AR, Oheb D, Zaslow TL. Gastrointestinal Prophylaxis in Sports Medicine. Sports health. 2018;10(2):152-5.

11. Fahlman $M$, Engels $H$, Morgan A, Kolokouri I. Mucosal IgA response to repeated wingate tests in females. International Journal of Sports Medicine. 2001;22(02):127-31.

12. Pedersen BK, Ullum $\mathrm{H}$. NK cell response to physical activity: possible mechanisms of action. Medicine and science in sports and exercise. 1994;26(2):140-6.

13. Friman G, Wesslén L. Infections and exercise in highperformance athletes. Immunology and cell biology. 2000;78(5):510-22.

14. Harris MD. Infectious disease in athletes. Current sports medicine reports. 2011;10(2):84-9.

15. Ahmadinejad Z, Alijani N, Mansori S, Ziaee V. Common sportsrelated infections: a review on clinical pictures, management and time to return to sports. Asian journal of sports medicine. 2014;5(1):1.

16. Pasricha S-R, Low M, Thompson J, Farrell A, De-Regil L-M. Iron supplementation benefits physical performance in women of reproductive age: a systematic review and meta-analysis. The Journal of Nutrition. 2014;144(6):906-14.

17. Mielgo-Ayuso J, Zourdos MC, Calleja-González J, Urdampilleta A, Ostojic S. Iron supplementation prevents a decline in iron stores and enhances strength performance in elite female volleyball players during the competitive season. Applied Physiology, Nutrition, and Metabolism. 2015;40(6):615-22.

18. Yıldız SA. Aerobik ve anaerobik kapasitenin anlamı nedir. Solunum dergisi. 2012;14(1):1-8.

19. Kocahan T, Akınoğlu B. Determination of the relationship between core endurance and isokinetic muscle strength of elite athletes. Journal of exercise rehabilitation. 2018;14(3):413.

20. Liese B, Rosenberg M, Schratz A. Programmes, partnerships, and governance for elimination and control of neglected tropical diseases. The Lancet. 2010;375(9708):67-76.

21. Wolfe MS. Giardiasis. Clinical microbiology reviews. 1992;5(1):93-100.

22. Robertson LJ, Crompton D, Sanjur D, Nesheim MC. Haemoglobin concentrations and concomitant infections of hookworm and Trichuris trichiura in Panamanian primary schoolchildren. Transactions of the Royal Society of Tropical Medicine and Hygiene. 1992;86(6):654-6.

23. Değerli S, Özçelik S, Çeliksöz A. Cumhuriyet Üniversitesi Tıp Fakültesi Parazitoloji laboratuvarına başvuran hastalarda bağırsak parazitlerinin dağılımı. Türkiye Parazitol Derg. 2005;29(2):116-9.
24. Cozon G. Iron deficiency and digestive disorders. Transfusion clinique et biologique: journal de la Societe francaise de transfusion sanguine. 2014;21(4-5):189-92.

25. Umbreit J. Iron deficiency: a concise review. American journal of hematology. 2005;78(3):225-31.

26. Berg A, Müller H, Rathmann S, Deibert P. The gastrointestinal system-an essential target organ of the athlete's health and physical performance. Exercise immunology review. 1999;5:7895.

27. Venkatraman JT, Pendergast DR. Effect of dietary intake on immune function in athletes. Sports medicine. 2002;32(5):32337.

28. Rajoo Y, Ambu S, Lim YA, Rajoo K, Tey SC, Lu CW, Ngui R. Neglected Intestinal Parasites, Malnutrition and Associated Key Factors: A Population Based Cross-Sectional Study among Indigenous Communities in Sarawak, Malaysia. PLoS One. 2017 Jan 17;12(1):e0170174.

29. Pedlar CR, Brugnara C, Bruinvels G, Burden R. Iron balance and iron supplementation for the female athlete: $A$ practical approach. European journal of sport science. 2018;18(2):295305.

30. Beard J, Tobin B. Iron status and exercise. The American journal of clinical nutrition. 2000;72(2):594S-7S.

31. Hinton PS. Iron and the endurance athlete. Applied Physiology, Nutrition, and Metabolism. 2014;39(9):1012-8.

32. Peters EM, Bateman ED. Ultramarathon running and upper respiratory tract infections. An epidemiological survey. $\mathrm{S}$ Afr Med J. 1983 Oct 1;64(15):582-4.

33. Nieman DC, Johanssen LM, Lee JW, Arabatzis K. Infectious episodes in runners before and after the Los Angeles Marathon. J Sports Med Phys Fitness. 1990;30(3):316-28.

34. Pedersen B, Rohde T, Zacho M. Immunity in athletes. The Journal of sports medicine and physical fitness. 1996;36(4):23645.

35. Zeyrek FY, Zeyrek CD. Alerjik hastalıklar ve parazitoz. Türkiye Parazitoloji Dergisi İzmir. 2006;30(2):135-40.

36. Sahlin K. Muscle energetics during explosive activities and potential effects of nutrition and training. Sports medicine. 2014;44(2):167-73.

37. Thompson BJ, Ryan ED, Sobolewski EJ, Smith-Ryan AE. Dietary protein intake is associated with maximal and explosive strength of the leg flexors in young and older blue collar workers. Nutrition Research. 2015;35(4):280-6. 